\title{
Role of natural killer (NK) cells during pregnancy: A review
}

\author{
Marcio Nogueira Rodrigues ${ }^{1}$, Phelipe Oliveira Favaron ${ }^{1}$, Jamille Gregório Dombrowski ${ }^{2}$, \\ Rodrigo Medeiros de Souza ${ }^{2,3}$, Maria Angelica Miglino ${ }^{1^{*}}$ \\ ${ }^{1}$ School of Veterinary Medicine and Animal Science, University of Sao Paulo, Sao Paulo, Brazil; \\ *Corresponding Author: miglino@usp.br \\ ${ }^{2}$ Institute of Biomedical Science, University of Sao Paulo, Sao Paulo, Brazil \\ ${ }^{3}$ Federal University of Acre, Cruzeiro do Sul, Brazil
}

Received 21 January 2013; revised 5 March 2013; accepted 8 April 2013

Copyright (c) 2013 Marcio Nogueira Rodrigues et al. This is an open access article distributed under the Creative Commons Attribution License, which permits unrestricted use, distribution, and reproduction in any medium, provided the original work is properly cited.

\section{ABSTRACT}

The homeostasis is maintained by the immune system which is constituted a network of organs, cells and molecules that act to combating the assaults affecting the body. The immune function has been conceptually divided into innate immunity and acquired immunity. Among the effector cells of innate immunity are the natural killer cells (NK), they play an important role in the reproductive immunology in the establishment and maintenance of pregnancy and fetus. The study of the biological mechanisms involved in the maintenance of pregnancy contributes to increase knowledge about immune tolerance. The way in which the immune system is modulated, and the study of the recognition systems maternal innate and adaptive occurring during pregnancy, allow to understand the survival of the fetus. The aim of this review was to present the main functions of NK cells and describe their role in the process of trophoblastic invasion in the deployment process, in the maternal-fetal interaction and development of the fetus. The knowledge of the precise role of NK cells is necessary, because these cells may be responsible for reactions which lead to embryonic and fetal loss during the organogenesis process.

Keywords: Reproduction; Natural Killer; Pregnancy; Imunne System

\section{INTRODUCTION}

The implantation process is a key requirement for re- production in viviparous species. The processes by which a blastocyst is accepted by the maternal endometrium are complex and require the interaction of different systems, including the immune system. Implantation occurs during a specific time within the "window of implantation" in which the maternal endometrium becomes receptive to the blastocyst, which is ready for invasion. The process of implantation and the maternal-foetal interaction during pregnancy represent a peculiar histoincompatible immunological status, which is characterized by the relationship between the foetal antigens and the maternal immune system [1].

Natural killer (NK) cells are lymphocytes that participate in the innate immune system (natural) as the first line of defence and appear to play a key role in reproductive immunology $[2,3]$. It is believed that immune system cells, NK cells in particular, are crucial for the induction of tolerance of the blastocyst during implantation. NK cells secrete an array of cytokines that are important during angiogenesis; therefore, these cells may contribute to placental development and the establishment of pregnancy [4].

NK cells are the most recently described of the immunocompetent cells and are still under investigation [5]. NK cells are large granular lymphocytes that populate the pregnant uterus and function in the immune surveillance against pathogens during pregnancy, protecting the mother and foetus. Important functions of these cells include migration and the secretion of extracellular matrix proteins and cytokines [6].

Phenotypically, NK cells are characterized by the expression of CD56 and CD16 receptors on the surface [2,7]. Based on the concentration of the CD56 antigen, NK cells can be divided into two subpopulations, CD56 $6^{\text {dim }}$ and CD56 $6^{\text {bright }}$. CD56 $6^{\text {dim }}$ cells demonstrate high 
cytotoxicity in vitro, whereas CD56 ${ }^{\text {bright }}$ cells exhibit a low cytotoxic capacity; however, the CD56 ${ }^{\text {bright }}$ cells produce important immunoregulatory cytokines, particularly interferon-gamma (IFN- $\gamma$ ) [2,8,9]. Approximately $90 \%$ of peripheral NK cells are CD56 ${ }^{\text {dim }}$ and express high levels of CD16, and the remaining $10 \%$ are CD56 ${ }^{\text {bright }}$ with minimal or no expression of CD16. Several studies have demonstrated that peripheral NK cells do not change during the menstrual cycle; however, a numerical and functional decrease has been observed during pregnancy $[2,8]$.

Studies have shown that endometrial NK cells participate in embryo-maternal interactions during implantation, trophoblast invasion, placentation, and foetal development, which represents a new perspective in the field of reproductive immunology [10].

An increase in the number of uterine natural killer (uNK) cells has been associated with reproductive failure. The reproductive failure mechanisms associated with a high uNK cell density are increased angiogenesis and blood flow during peri-implantation, which can lead to early maternal circulation and cause pregnancy failure because of excessive oxidative stress. Given the importance of uNK cells for the establishment and maintenance of pregnancy, the purpose of this review is to collate data on the possible implications of endometrial NK cells in the process of embryo implantation and the development and progression of pregnancy.

\section{FUNCTIONS OF NK CELLS ASE OF USE}

The actual functions of NK cells are unknown [11]. NK cells are considered "non-specific" lymphocytes because they kill infected and transformed cells without prior sensitization. However, NK cells exhibit a welldefined specificity, which is sometimes rather subtle, and contain a complex system of receptors [12]. Cytotoxicity is the best characterised effector function of NK cells, and in humans, these cells efficiently lyse abnormal cells that do not express HLA-I or express inadequate amounts of HLA-I [13]. The recognition of appropriate targets is the first key step in the activation of cytotoxicity. Therefore, although NK cells express conventional activating receptors, they also constitutively express inhibitory receptors [12]. The inhibitory receptors regulate NK-cell activity by interrupting intracellular signalling when major histocompatibility complex class I (MHC-I) molecules are properly expressed; activating receptors, a number of which have ligands that are not MHC-I molecules, initiate the NK cell responses against infected cells [14].

The activity of NK cells is regulated by their interacttion with cytokines and other factors. Although they are components of the innate immune response, NK cells also interact constantly with the adaptive immune response. These cells can lyse antigen-presenting target cells that are recognised as non-self or cells that do not express self-molecules on their surface. Human leukocyte antigen (HLA) molecules interact with the NK-cell inhibitory receptors, known as killer-cell immunoglobulin-like receptors (KIR), to protect the trophoblast cells (at the maternal-foetal interface) against the NK cell-mediated lysis that occurs because of the low expression of MHC class I molecules [15-17].

It was reported that NK cells constitute $50 \%-90 \%$ of the leukocytes in the decidua, whereas $\mathrm{B}$ and $\mathrm{T}$ cells are rare cell types in this region [18]. The NK cells in the decidua are different from those found in the peripheral blood; uNK cells are specialised in the secretion of cytokines. Through this secretion, NK cells regulate the levels of the cytokines responsible for changes in the anatomical compliance of the decidual arteries. The decidual spiral arteries undergo a remodelling process to provide the necessary nutrients for the development of the embryo/foetus [11]. There is an interaction between the non-classical (HLA-G and HLA-E) and classical (HLAC) MHC class I antigen-presenting molecules during the arterial remodelling [18].

During pregnancy, uNK cells are found in close proximity to the implantation site and in intimate contact with the extravillous trophoblast [19]. The increase in uNK cells in early pregnancy, their hormonal dependence, and strong proximity to the trophoblast suggest that uNKs play an important role in regulating the maternal immune response to the foetal allograft, controlling the trophoblast growth and the invasion and development of the placenta during human pregnancy [19].

\section{ROLE OF NK CELLS IN TROPHOBLASTIC INVASION}

To establish a normal pregnancy, the trophoblast must physiologically invade the maternal decidua, creating a low-resistance blood flow to promote adequate oxygenation for the development of the foetal placental unit and decreasing the influence of vasomotor variations [9].

Trophoblast cells exhibit specific immunological characteristics, particularly with respect to the expression of HLA; the cells express HLA-C, HLA-G, and HLA-E but do not express the non-classical histocompatibility molecules A, B, DR, DQ, and DP, which is a potential explanation for the maternal non-rejection of the foetus [20]. Although the biological function is not understood completely, the HLA-G molecules expressed by trophoblast cells appear to protect against the lysis mediated by NK cells [21,22].

The cytokines produced by the mother can act as a placental growth factor, limit trophoblast invasion, and mediate tissue remodelling. The proliferative and inva- 
sive nature of the trophoblast must be regulated precisely to ensure that the endometrium remains intact and is not invaded by the growing placenta. This regulation is mediated in part by selective cell apoptosis, a process that does not alter the normal structure of the tissue [23]. It was also demonstrated that the protective effect resulted from the binding of trophoblast cells to the inhibitory receptors in NK cells, known as killer cell immunoglobulin-like receptors (KIRs) [23]. These receptors transmit inhibitory signals that inhibit the activation of NK cells.

The trophoblastic invasion is highly regulated, and uNK cells play a key role in controlling this process [11]. Endometrial NK cells exhibit important functions during trophoblast invasion through the production of cytokines, which involves mechanisms such as cytotoxicity and the induction of apoptosis in trophoblastic cells [24].

In vitro studies involving a number of the cytokines and growth factors produced by endometrial NK cells demonstrated the inhibitory effect of a number of factors, such as TNF- $\alpha$ and IFN- $\gamma$ [25]. It reported that IL-5 stimulates uNK cells in vitro, which in turn stimulates trophoblastic and cytotrophoblastic invasion [26]. In vitro studies demonstrated the interaction between the trophoblast and uNK cells [9]. These interactions induced the production of several cytokines and growth factors related to placental development, including the following: 1) tumour necrosis factor (TNF- $\alpha)$; 2) interferon gamma (IFN- $\gamma)$; 3) granulocyte macrophage colony-stimulating factor (GM-CSF); and 4) macrophage inhibitory factor (MIF) [9,24,25].

NK cells maintain close contact with the extravillous trophoblastic tissue and express receptors that recognise the surface antigens in trophoblast cells. Unlike peripheral NK cells, endometrial NK cells exhibit low cytotoxicity against the trophoblast. The extravillous trophoblast cells do not express the human leukocyte antigen (HLA) class 2; however, HLA class 1 molecules are expressed in trophoblast cells and are recognised by endometrial NK cells [24].

It has been suggested that an inappropriate trophoblastic invasion mediated by endometrial NK cells is one of the mechanisms responsible for early pregnancy loss [27]. Studies have reported a higher number of NK cells in the decidua after the miscarriage of foetuses with chromosomal abnormalities compared to chromosomally normal foetuses [28], demonstrating that endometrial NK cells play an important role in the trophoblastic invasion process.

\section{ROLE OF NK CELLS IN THE PLACENTATION PROCESS}

NK cells are the predominant cell type found in the human placenta in early pregnancy [29]. These cells con- stitute $60 \%$ to $70 \%$ of the total lymphocytes in the placenta and are located in the glandular epithelium of the endometrium and around small arteries [30]. The function of the NK cells during this period has not been established; however, the cells are assumed to be essential for placental development and at the maternal-foetal interface [29]. Most hypotheses regarding the potential functions of these cells are derived from detailed investigations performed in mice and humans exhibiting a haemochorial placenta. In these studies, NK cells were detected during the decidualization of the placenta and participated in endometrial angiogenesis [31,32]. In cattle, studies have demonstrated that the distribution of lymphocytes was lower in the caruncular and intercaruncular regions of pregnant cows compared with nonpregnant cows. In addition, a significant reduction in the number of lymphocytes in the bovine uterine epithelium was observed between 19 and 27 days after fertilisation [33].

The interaction of NK cells with CD1d in trophoblast cells plays a specific role at the maternal-foetal interface, promoting the active induction of immune tolerance and the development of the placenta [34]. In the absence of uNK cells, significant changes occur in the endometrium, such as modifications to the decidual arteries, hypocellularity or necrosis of the decidua, and decreases in placental development [35]. It is presumed that the presence of uNK cells in the maternal-foetal compartment is essential for the appropriate growth of the placenta [36].

During pregnancy, the architecture of the spiral arteries is significantly modified by angiogenesis, which develops and establishes a flow adequate for decidual development and embryo implantation. The perivascular location of the endometrial NK cells and the detection of vascular endothelial growth factor (VEGF) expression suggest the participation of these cells in the placental development process [27].

The remodelling of the spiral arteries is a key characteristic of early placental development in human pregnancy, and the failure of this process has been associated with severe problems and complications during pregnancy, including preeclampsia, foetal growth restriction, and miscarriage [4]. The uNK cells are often clustered around the spiral arteries and arterioles during the early phase of pregnancy, and this distribution may reflect the role that uNK cells play in mediating vascular changes during pregnancy [11].

In vitro models using chorionic arteries from full-term human placentas and myometrial arteries from non-pregnant individuals demonstrated that uNK cell supernatants at 8 - 10 weeks of gestation initiate the separation of vascular smooth muscle cells, promoting vascular differentiation [37-39]. It reported that uNK cells stimulate the angiogenesis of endothelial cells in vitro and in vivo, 
leading to an assessment of the contribution of these cells to placental angiogenesis during pregnancy [26]. A possible role for uNK cells during this process is the development of vascular smooth muscle in newly formed vessels [11]. It was observed a large number of uNK cells around the uterine arteries in Cricetidae rodent placentas, demonstrating the migration of these cells during placentation during blood vessel remodelling [40].

\section{ROLE OF NK CELLS IN THE EMBRYO-MATERNAL INTERACTION}

During pregnancy, the embryo is recognised by the maternal immune system without triggering an immune response against the permanence and development of the embryo, which occurs under any other circumstances involving exposure to antigens. Therefore, the maternal immune system ensures a favourable environment for the development of the foetus. This phenomenon is termed "immune tolerance" [41].

The primary sites of direct contact between the cells derived from the foetus and the maternal immunocompetent cells is the maternal-foetal interface in the uterus (particularly at the site of implantation), in the maternal arteries, and in the intervillous space in the human placenta [42].

Several factors are involved in this complex immunoregulatory network that results in the tolerance and regulation of foetal development and includes the recognition of the paternal major histocompatibility complex (MHC) (expressed by the embryo), the control of the direct cytotoxicity of uNK cells, the activity of regulatory $\mathrm{T}$ cells, the release of different cytokines, and the hormonal influence on the maternal immune system [43].

Throughout pregnancy, the immune response is modulated at the maternal-foetal interface. In addition to specialised immune cells, cytokines can be derived from the activation of $\mathrm{T}$ helper cells and from the activity of macrophages and NK cells in the innate immune response and in the decidual epithelium and placental stroma, which are the sites of partial induction of maternal tolerance $[44,45]$.

The MHC class I is critical for antigen presentation to cytotoxic T cells and NK cells and is present in almost all nucleated cells in the body; however, MHC class I is not expressed by the foetal trophoblast cells. This mechanism is crucial for placental and foetal protection against aggression by the maternal immune system [46,47].

The maternal-foetal interface is also characterised by the unique activity of complement regulatory proteins, uNK cells, macrophages, T cells of different phenotypes, and cytokines in the local environment [48]. In humans, the numbers of $\mathrm{T}$ and NK cells increase in the basal decidua (implantation site), suggesting that these cells accumulate at the maternal-foetal interface and play an important role in the maintenance of implantation during pregnancy [49].

The actual function of NK cells in the maternal-foetal interface has not been defined clearly; however, several hypotheses have been proposed, such as the control of extravillous invasion, control of uterine vascular remodelling, and local anti-viral action [50].

\section{A ROLE OF NK CELLS IN FOETAL DEVELOPMENT}

Several studies have demonstrated numerous aggregates of T and B cells, macrophages, mast cells, and eosinophils in the normal human uterus. However, after implantation, the aggregates of $\mathrm{T}$ and $\mathrm{B}$ cells disappear, eosinophils and mast cells become scarce, and there is a clear predominance of NK cells and macrophages [51].

HLA-G is a molecule of great importance for the regulation of pregnancy and plays a key role in maintaining an immunosuppressive environment for foetal acceptance [52]. The interaction of the HLA-G molecule with inhibitory or activating receptors on the surface of NK cells prevents the lysis of trophoblast cells [53] or activates the production of cytokines that promote the remodelling of the vasculature in the maternal-foetal region, which is important for developing a proper oxygen supply to the foetus $[18,24,54]$. A new mechanism of immunosuppression by HLA-G has been described in which activated T lymphocytes and NK cells acquire HLA-G via a membrane transfer mechanism termed "trogocytosis”, and these cells exert an immunosuppressive function [55].

HLA-G effectively inhibits cells that could attack the foetus, such as NK cells. NK cells exhibit cytotoxic activity without the prior recognition of an antigen. In addition to expressing activating and inhibitory receptors on their surface, NK cells recognise molecular patterns and are regulated by cytokines [56].

NK cells not only attack cells derived from the foetus but also secrete cytokines that induce inflammation. Although we associate an NK response as harmful to the foetus, these cells play an important role in early pregnancy during vascular formation and the remodelling of the maternal-foetal interface region, allowing formation of the oxygen supply required for foetal development. In late pregnancy, the number of regulatory $\mathrm{T}$ lymphocytes and NK cells circulating in the blood decreases [57].

\section{IDENTIFICATION OF UNK CELLS}

Uterine sections from pregnant rats demonstrated a selective reaction to staining with the lectin Dolichos biflorus agglutinin (DBA) at all gestation days, and this reaction was not observed in virgin uteri. The positive reaction to the DBA staining coupled with cytochemical 
staining for periodic acid Schiff (PAS) on the cell surface and in the cytoplasmic granules of uNK cells was examined by light microscopy. The DBA lectin reacted with the same cells that were stained with the PAS, suggesting the simultaneous use of these two staining techniques for the identification of these cells in the placenta of murine rodents. These data suggest the high selectivity of DBA lectin for the recognition of uNK cells [58]. Previous immunohistochemical studies of pregnant rat uteri using lectin to identify uNK cells have been reported $[59,60]$. The positive reactions on the cell surface and in the cytoplasmic granules were inhibited completely by $\mathrm{N}$-acetylgalactosamine (GalNAc), a specific inhibitory sugar of DBA lectin, which characterised the acquisition of glycoconjugates containing GalNAc as a differentiation step in the lineage that was shown only by the NK cells that reach the pregnant uterus [61]. However, some authors [40] reported that although the DBA-lectin staining was not specific for uNK cells in the placenta of Cricetidae rodents and reacted in cells within the labyrinth, the endothelium of foetal capillaries, and the yolk-sac epithetlium, the use of the cytochemical reaction for PAS coupled with the immunohistochemical staining for vimentin may help identify uNK cells in the developing placental disc.

\section{CONCLUSION}

There is no absolute evidence that uNK cells play a destructive role and attack placental or even embryonic cells during pregnancy. However, the abnormal regulation of NK cells in the uterus and/or in the blood can cause failures during implantation or embryo loss during pregnancy; studies have demonstrated the association of uNK cells with reproductive failure when found in small numbers in the pregnant uterus. Studies must be performed to demonstrate the activity of uNK cells during the different gestational periods to elucidate the effects of these cells in reproductive immunology.

\section{REFERENCES}

[1] Somigliana, E., Viganò, P. and Vignali, M. (1999) Endometriosis and unexplained recurrent spontaneous abortion: Pathological states resulting from aberrant modulation of natural killer cell function? Human Reproduction Update, 5, 40-51. doi:10.1093/humupd/5.1.40

[2] Raí, R., Sacks, G. and Trew, G. (2005) Natural killer cells and reprodutive failure: Theory, practice and prejudice. Human Reproduction, 20, 1123-1126. doi:10.1093/humrep/deh804

[3] Zhang, J., Croy, B.A. and Tian, Z. (2005) Uterine natural killer cells: Their choices, their missions. Cellular \& Molecular Immunology, 2, 123-139.

[4] Pijnenborg, R., Vercruysse, L. and Hanssens, M. (2006) The uterine spiral arteries in human pregnancy: Facts and controversies. Placenta, 27, 939-958. doi:10.1016/j.placenta.2005.12.006

[5] Croy, B.A., Yu, Z.M. and King, G.J. (1994) A review of the natural killer cell lineage in the uterus of the mouse and of the pig. Journal of Animal Science, 72, 9-15.

[6] Croy, B.A., Reed, N., Malashenko, B.A., Kim, K. and Kown, B.S. (1991) Demonstration of YAC target cell lysis by murine granulated metrial gland cells. Cellular Immunology, 133, 116-126. doi:10.1016/0008-8749(91)90184-D

[7] Abbas, A.K. and Lichtman, A.H. (2005) Imunologia celular E molecular. 5th Edition, Elsevier, Amsterdam.

[8] Lanier, L.L. (2001) On guard-activating NK cell receptors. Nature Immunology, 2, 23-27. doi:10.1038/83130

[9] Quenby, S. (2006) Uterine natural killer cells, implanttation failure and recurrent miscarriage. Reproductive Biomedicine Online, 13, 24-28. doi:10.1016/S1472-6483(10)62012-3

[10] Fettback, P.B.T., Domingues, T.S., Hassun Filho, P.A., Motta, E.L.A., Serafini, P.C. and Baracat, E.C. (2009) Endometrial natural killer cells: What are they? What do they do? What do we need to know? Femina, 37, 373378.

[11] Lash, G.E. and Bulmer, J.N. (2011) Do uterine natural killer (uNK) cells contribute to female reproductive disorders? Journal of Reproductive Immunology, 88, 156-164. doi:10.1016/j.jri.2011.01.003

[12] O’Connor, G.M., Hart, O.M. and Gardiner, C.M. (2005) Putting the natural killer cell in its place. Immunology, 117, 1-10. doi:10.1111/j.1365-2567.2005.02256.x

[13] Biassoni, R., Cantoni, C., Falco, M., Pende, D., Millo, R., Moretta, L., Bottino, C. and Moretta, A. (2000) Human natural killer cell activating receptors. Molecular Immunology, 37, 1015-1024. doi:10.1016/S0161-5890(01)00018-9

[14] Kelley, J., Walter, L. and Trowsdale, J. (2005) Comparative genomics of natural killer. Cellular \& Molecular Immunology, 2, 123-129.

[15] Emmer, P.M., Veerhoek, M., Nelen, W.L.D.M., Steegers, E.A.P. and Joosten, I. (1999) Natural killer cell reactivity and HLA-G in recurrent spontaneous abortion. Transplantation Proceedings, 31, 1838-1840. doi:10.1016/S0041-1345(99)00182-7

[16] Pazmany, L., Mandelboin, O., Vales-Gomez, M., Davis, D.M., Becker, T.C., Reyburn, H.T., Seebach, J.D., Hill, J.A. and Strominger, J.L. (1999) Human leucocyte antigen-G and its recognition by natural killer cells. Journal of Reproductive Immunology, 43, 127-137. doi:10.1016/S0165-0378(99)00028-5

[17] Rousseau, P., Paul, P., O’Brien, M., Dausset, J., Carosella, E.D. and Moreau, P. (2000) The X1 box of HLA-G promoter is a target site for RFX and Sp1 factors. Human Immunology, 61, 1132-1137. doi:10.1016/S0198-8859(00)00199-3

[18] Parham, P. (2004) NK cells and trophoblasts: Partners in pregnancy. The Journal of Experimental Medicine, 200, 951-955. doi:10.1084/jem.20041783

[19] Dosiou, C. and Giudice, L.C. (2006) Natural killer cells 
in pregnancy and recurrent pregnancy loss: Endocrine and immunologic perspectives. Endocrine Reviews, 26, 44-62. doi:10.1210/er.2003-0021

[20] Hunter, H., Hammer, A., Dohr, G. and Hunt J.S. (1998) HLA expression at the maternal-fetal interface. Clinical and Developmental Immunology, 6, 197-204.

[21] Chumbley, G., King, A., Gardner, L., Howlett, S., Holmes, N. and Loke, Y.W. (1994) Generation of an antibody to HLA-G in transgenic mice and demonstration of the tissue reactivity of this antibody. Journal of Reproductive Immunology, 27, 173-186. doi:10.1016/0165-0378(94)90002-7

[22] King, A., Hilby, S.E., Verma, S., Burrows, T., Gardner, L. and Loke, Y.W. (1997) Uterine NK cells and trophoblast HLA class I molecules. American Journal of Reproductive Immunology, 37, 459-462. doi:10.1111/j.1600-0897.1997.tb00260.x

[23] Ghosh, D., Sharkey, A.M., Charnock-Jones, D.S., Dhawan, L., Dhara, S., Smith, S.K. and Sengupta, J. (2000) Expression of vascular endothelial growth factor (VEGF) and placental growth factor (PIGF) in conceptus and endometrium during implantation in the rhesus monkey. Molecular Human Reproduction, 6, 935-941. doi:10.1093/molehr/6.10.935

[24] Moffett-King, A. (2002) Natural killer cells and pregnancy. Nature Reviews Immunology, 2, 656-663. doi:10.1038/nri886

[25] Arcuri, F., Cintorino, M. and Carducci, A. (2006) Human decidual natural killer cells are a source and target of macrophage migration inhibitory factor. Reproduction, 131, 175-182. doi:10.1530/rep.1.00857

[26] Hanna, J., Goldman-Wohl, D., Hamani, Y., Avraham, I., Greenfield, C., Natanson-Yaron, S., Prus, D., Cohen-Daniel, L., Arnon, T.I., Manaster, I., Gazit, R., Yutkin, V., Benharroch, D., Porgador, A., Keshet, E., Yagel, S. and Mandelboim, O. (2006) Decidual NK cell regulate key developmental processes at the human fetal-maternal interface. Nature Medicine, 12, 1065-1074. doi:10.1038/nm1452

[27] Zhang, J., Chen, Z., Smith, G.N. and Croy, B.A. (2011) Natural killer cell-triggered vascular transformation: Maternal care before birth? Cellular \& Molecular Immunology, 8, 1-11.

[28] Quack, Q.C., Vassiliadou, N., Pudney, J., Anderson, D.J. and Hill, J.A. (2001) Leucocyte activation in the decidua of chromosomally normal and abnormal fetuses from women with recurrent abortion. Human Reproduction, 16, 949-955. doi:10.1093/humrep/16.5.949

[29] Elami-Suzin, M. and Mankuta, D. (2007) Role of natural killer cells in normal pregnancy and recurrent pregnancy loss. Harefuah, 146, 140-144.

[30] Ashkar, A.A. and Croy, B.A. (2001) Functions of uterine natural killer cells are mediated by interferon gamma production during murine pregnancy. Seminars in Immunology, 13, 235-241. doi:10.1006/smim.2000.0319

[31] Tayade, C., Fang, Y. and Croy, B.A. (2007) A review of gene expression in porcine endometrial lymphocytes, endothelium and trophoblast during pregnancy success and failure. Journal of Reproduction and Development, 53,

\section{5-463. doi:10.1262/jrd.18170}

[32] Oh, M.J. and Croy, B.A.A. (2008) A map of relationships between uterine natural killer cells and progesterone receptor expressing cells during mouse pregnancy. Placenta, 29, 317-323. doi:10.1016/j.placenta.2008.01.003

[33] Gogolin-Ewens, J.K., Lee, C.S., Mercer, W.R. and Brandon, M.R. (1989) Site-directed differences in the immune response to the fetus. Immunology, 66, 312-317.

[34] Boyson, J.E., Rybalov, B., Koopman, L.A., Exley, M., Balk, S.P., Racke, F.K., Masch, R., Schatz, F., Brian Wilson, S. and Strominger, J.L. (2002) CD1d and invariant NKT cells at the human maternal-fetal interface. Proceedings of the National Academy of Sciences, 99, 1374113746. doi:10.1073/pnas.162491699

[35] Ashkar, A.A., Black, J.P., Wei, Q., He, H., Liang, L., Head, J.R. and Croy, B.A. (2003) Assessment of requirements for IL 15 and INF regulatory factors in uterine NK cell differentiation and function during pregnancy. Journal of Immunology, 171, 2937-2944.

[36] Guimond, M.J., Wang, B. and Croy, B.A. (1999) Immune competence involving the natural killer linage promotes placental growth. Placenta, 20, 441-450. doi:10.1053/plac.1999.0398

[37] Robson, A., Innes, B.A., Lash, G.E., Robson, S.C. and Bulmer, J.N. (2010) Uterine natural killer cells promote vascular smooth muscle cell dedifferentiation in a vessel culture model. Reproductive Sciences, 17, 324A.

[38] Lash, G.E. (2010) Functional role of uterine natural killer cells in early human pregnancy. Journal of Reproductive Immunology, 31, S87-S92.

[39] Harris, L.K., Robson, A., Lash, G.E., Aplin, J.D., Baker, P.N. and Bulmer, J.N. (2010) Physiological remodelling of the uterine spiral arteries during human pregnancy: Uterine natural killer cells mediate smooth muscle cell disruption. Proceedings of the Physiological Society, 19, C42.

[40] Favaron, P.O., Carter, A.M., Ambrósio, C.E., Morini, A.C., Mess, A.M., Oliveira, M.F. and Miglino, M.A. (2011) Placentation in Sigmodontinae: A rodent taxon native to South America. Reproductive Biology and Endocrinology, 9, 55. doi:10.1186/1477-7827-9-55

[41] Michelon, T., Silveira, J.G., Graudenz, M. and Neumann, L. (2006) Imunologia da gestação. Revista da Associação Médica do Rio Grande do Sul, 50, 145-151.

[42] Christiansen, O.B. (2005) A fresh look at the causes and treatments of recurrent cell receptor gene clusters. PLoS Genetics, 1, 129-139.

[43] Sarafana, S., Coelho, R., Neves, A. and Trindade, J.C. (2007) Aspectos da imunologia da gravidez. Acta Medica Portuguesa, 20, 355-358.

[44] Wilczynsky, J.R. (2005) Th1/Th2 cytokines balance-Yin and yang of reproductive immunology. European Journal of Obstetrics Gynecology and Reproductive Biology, 122, 136-143. doi:10.1016/j.ejogrb.2005.03.008

[45] Tizard, I.R. (2009) Imunidade no feto e no recém nascido, Elsevier, São Paulo.

[46] Davies, C.J., Fisheer, P.J. and Schafler, D.H. (2000) Temporal and regional of major histocompatibility com- 
plex class I expression at the bovine uterine/placental interface. Placenta, 21, 194-202. doi:10.1053/plac.1999.0475

[47] Huddleston, H. and Schust, D.J. (2004) Immune interactions at the maternal-fetal interface: A focus on antigen presentation. American Journal of Reproduction, 51, 283289. doi:10.1111/j.1600-0897.2004.00157.x

[48] Morena, M. and Gitlin, J.D. (2004) The immunology of pregnancy. In: Stiehm, E.R., Ochs, H.D. and Winkelstein, J.A., Eds., Immunologic Disorders in Infant \& Children, 5th Edition, Elsevier Saunders, Philadelphia, 273-285.

[49] Saito, S., Nakashima, A., Shiozaki, A., Ito, M. and Sasachhi, Y. (2007) What is the role of regulatory T cells in the success of implantation and early pregnancy? Journal Assisted Reproductions and Genetics, 24, 379-386. doi:10.1007/s10815-007-9140-y

[50] Tabiasco, J., Rabot, M., Aguerre-Girr, M., El Costa, H., Berrebi, A., Parant, O., Laskarin, G., Juretic, K., Bensussan, A., Rukavina, D. and Le Bouteiller, P. (2006) Human decidual NK cells: Unique phenotype and functional properties-A review. Placenta, 27, 34-39. doi:10.1016/i.placenta.2006.01.009

[51] Hunt, J.S., Petroff, M.G. and Burnett, T.G. (2000) Uterine leukocytes: Key players in pregnancy. Seminars in Cell \& Developmental Biology, 11, 127-137. doi:10.1006/scdb.2000.0158

[52] Kovats, S., Main, E.K., Librach, C., Stubblebine, M., Fisher, S.J. and DeMars, R. (1990) A class I antigen, HLAG, expressed in human trophoblasts. Science, 248, 220223. doi:10.1126/science.2326636

[53] Ponte, M., Cantoni, C., Biassoni, R., Tradori-Cappai, A., Bentivoglio, G., Vitale, C., Bertone, S., Moretta, A., Moretta, L. and Mingari, M.C. (1999) Inhibitory receptors sensing HLA-G1 molecules in pregnancy: Deciduaassociated natural killer cells express LIR-1 and CD94/ NKG2A and acquire p49, an HLA-G1-specific receptor. Proceedings of the National Academy of Sciences, 96, 5674-5679. doi:10.1073/pnas.96.10.5674
[54] Loke, Y.W. and King, A. (2000) Decidual natural killer cell interaction with trophoblast: Cytolysis or cytokine production? Biochemical Society Transactions, 28, 196198.

[55] Caumartin, J., Favier, B., Daouya, M., Guillard, C., Moreau, P., Carosella, E.D. and LeMaoult, J. (2007) Trogocytosis-based generation of suppressive NK cells. The EMBO Journal, 26, 1423-1433. doi:10.1038/sj.emboj.7601570

[56] Feger, U., Tolosa, E., Huang, Y.H., Waschbisch, A., Biedermann, T., Melms, A. and Wiendl, H. (2007) HLA-G expression defines a novel regulatory $\mathrm{T}$ cell subset present in human peripheral blood and sites of inflammation. Blood, 110, 568-577. doi:10.1182/blood-2006-11-057125

[57] LeMaoult, J., Caumartin, J., Daouya, M., Favier, B., Le Rond, S., Gonzalez, A. and Carosella, E.D. (2007) Immune regulation by pretenders: Cell-to-cell transfers of HLA-G make effector T cells act as regulatory cells. Blood, 109, 2040-2048. doi:10.1182/blood-2006-05-024547

[58] Paffaro Jr., V.A., Bizinotto, M.C., Joazeiro, P.P. and Yamada, A.T. (2003) Subset classification of mouse uterine natural killer cells by DBA lectin reactivity. Placenta, 24, 479-488. doi:10.1053/plac.2002.0919

[59] Damjanov, A. and Damjanov, I. (1992) Isolation of serine protease from granulated metrial gland cells of mice and rats with lectin from Dolichos biflorus. Journal of Reproduction and Fertility, 95, 679-684. doi:10.1530/jrf.0.0950679

[60] Stewart, I.J and Webster, A.J. (1997) Lectin histochemical studies of mouse granulated metrial gland cells. Histochemical Journal, 29, 885-892. doi:10.1023/A:1026498025550

[61] Wu, A.M. and Sugii, S. (1988) Differential binding properties of GalNac and/or Gal specific lectins. In: Wu, A.M. and Adams, L.G., Eds., Advances Experimental Medicine and Biology, Plenum Press, New York, 205-263. 